\title{
Predicting Parental Distress among Children Newly Diagnosed with Craniopharyngioma
}

\author{
Rachel K. Peterson ${ }^{1}$, Jason M. Ashford ${ }^{1}$, Sarah M. Scott ${ }^{1}$, Fang Wang ${ }^{2}$, Hui Zhang ${ }^{2}$, Julie A. \\ Bradley $^{3}$, Thomas E. Merchant ${ }^{4}$, and Heather M. Conklin ${ }^{1}$ \\ ${ }^{1}$ Department of Psychology, St. Jude Children's Research Hospital, Memphis, TN \\ 2Biostatistics, St. Jude Children's Research Hospital, Memphis, TN \\ ${ }^{3}$ University of Florida Health Proton Therapy Institute, 2015 North Jefferson Street, Jacksonville, \\ FL 32206 \\ ${ }^{4}$ Department of Radiation Oncology, St. Jude Children's Research Hospital Memphis, TN
}

\begin{abstract}
Background-Childhood brain tumor diagnoses are stressful for families. Children diagnosed with craniopharyngioma $(\mathrm{Cp})$ present with particularly challenging medical and cognitive problems due to tumor location and associated biophysiologic comorbidities. This study examined parental distress in a sample of Cp patient families treated with proton beam therapy to identify factors for targeting psychological intervention.
\end{abstract}

Procedure-Prior to $(n=96)$ and one year after $(n=73)$ proton therapy, parents of children diagnosed with $\mathrm{Cp}(9.81 \pm 4.42$ years at baseline; $49 \%$ male) completed a self-report measure of distress, the Brief Symptom Inventory (BSI). Children completed cognitive assessment measures at baseline; medical variables were extracted from the study database.

Results-At baseline, t-tests revealed parents reported higher levels of distress than normative expectations on Anxiety, Depression, Global Severity, and Positive Symptom Distress BSI scales ( $p<.05$ ). Linear mixed effects models revealed parent report measures of child executive dysfunction and behavioral issues were more predictive of parental distress than patients' cognitive performance or medical status ( $p<.05)$. Models also revealed a significant reduction only in Anxiety over time $(t=-2.19, p<.05)$. Extensive hypothalamic involvement at baseline predicted this reduction $(p<.05)$.

Conclusion-Parents are experiencing significant distress before their child begins adjuvant therapy for $\mathrm{Cp}$, though parental distress appears largely unrelated to medical complications and more related to parent perceptions of child cognitive difficulties (versus child performance). Importantly, this may be explained by a negative parent reporting style among distressed parents.

\footnotetext{
"Corresponding Author: Heather M. Conklin, Department of Psychology, Mail Stop \#740, St. Jude Children's Research Hospital, 262 Danny Thomas Place, Memphis, Tennessee 38105. Telephone: 901-595-3585. Fax: 901-595-4701. heather.conklin@ stjude.org. Corresponding author: Heather Conklin, Ph.D., 262 Danny Thomas Place, Mail Stop 740, Memphis, TN, 38105; 901-595-3300; heather.conklin@stjude.org

CONFLICT OF INTEREST STATEMENT

No potential conflicts of interest.
} 
Knowledge of socio-emotional functioning in parents related to patient characteristics is important for optimization of psychological intervention.

\section{Keywords}

craniopharyngioma; pediatric brain tumor; parental distress

\section{INTRODUCTION}

The diagnosis and treatment of a childhood brain tumor has a significant impact not only on the child but also his or her family. While parents generally adjust well to the pediatric cancer experience, a considerable number of parents continue to experience psychological distress, anxiety, and symptoms of post-traumatic-stress after termination of their child's cancer treatments [1-8]. Parents of these children may experience significantly worse quality of life (QoL) across the domains of physical functioning, general health, social functioning, and mental health [9-11]. Moreover, they may report feelings related to insecurity, lack of control in everyday living, greater reliance and dependence on others, chaos, and loneliness [10]. Some researchers [5, 12-15] have found that feelings of uncertainty, disease-related fear, and loneliness do not diminish overtime, and feelings of loneliness may increase over time [5].

Some predictors of parental maladjustment following a child's cancer diagnosis have been identified in the literature. For example, mothers of children with cancer report more psychological distress and perceived family conflict than their spouses [16]. In addition, while psychological distress tends to decrease over time for both parents, mothers have been found to report slightly more emotional distress than fathers up to one year post-diagnosis [17-18]. Other negative predictors of parental adjustment include low socioeconomic status (SES), recurrence of the disease in the child, limited access to social support, and worse health status of the child $[6,15,19]$. Though child cognitive functioning as a predictor of parental distress has not been reported in the oncology literature, having a child with greater cognitive difficulties following traumatic brain injury is associated with greater parental distress [20-22]. In contrast, for parents of children with cancer, social support, familial cohesion, and adaptability have been found to be associated with lower parental anxiety, distress and post-traumatic-stress symptoms [19, 23-26]. For example, parental adaptive style has been found to be a predictor of post-traumatic stress in guardians, as individuals that fall under the category of Low Anxiety or Repressor on the Adaptive Style Paradigm report healthier emotional functioning [27-31].

Parents of children with Craniopharyngioma (Cp) may be at particular risk of psychosocial difficulties due to the unique medical challenges of $\mathrm{Cp}$. Cps are histologically benign tumors located at the base of the brain above the pituitary gland and close to critical vasculature. While the overall survival rate is high (>80\%), there is a high morbidity risk secondary to tumor and treatment given tumor location [32-33]. Specifically, individuals diagnosed with $\mathrm{Cp}$ are at risk for headaches, nausea and/or vomiting secondary to hydrocephalus, vision changes, endocrinopathies, increased fatigue or sleepiness, and mood and/or behavior 
changes. Studies report reduced health-related QoL and high levels of psychosocial morbidity [33-36].

Although $\mathrm{Cp}$ is a benign entity, the treatment mirrors the treatment for malignant brain tumors and routinely involves surgery and/or radiation therapy. Proton therapy, a relatively newer form of radiation therapy, has notable potential benefits over conventional radiation therapy using photons including potential sparing of greater volumes of normal brain tissue. Initial studies have shown better preservation of intellectual functioning and processing speed with proton therapy [37-38], but are limited by factors such as small sample sizes, missing data, and lack of appropriate control groups. We have previously shown that children treated for $\mathrm{Cp}$ show weaker cognitive performance in comparison to normative expectations prior to proton therapy, resulting from tumor effects and surgical intervention [39].

Given the active role parents play in the treatment of childhood brain tumors, better understanding of their emotional functioning can provide a fuller picture of the support needed to help families cope [65]. The present study investigated parental distress in a sample of Cp patient families to identify associated clinical and cognitive factors for targeted intervention. More specifically, parental distress was measured prior to proton beam radiation as well as one year post-treatment to identify predictors of distress at presentation and examine how parental distress may change overtime. Based on the existing literature, we hypothesized elevated parental distress at baseline that would persist a year later among some caregivers. We also hypothesized child characteristics such as increased rate of endocrinopathies or executive dysfunction, which may require greater parental management, would predict greater parental distress.

\section{METHODS}

\section{Participants}

From August 2011 to May 2016, patients diagnosed with $\mathrm{Cp}(\mathrm{N}=110)$ were enrolled on a phase II trial of limited surgical intervention (resection) and proton beam radiation therapy. Participants were pediatric patients from infancy through 21 years of age diagnosed with $\mathrm{Cp}$ by histology, cytology, or neuroimaging. Patients with a history of treatment with fractionated radiation therapy, intracystic P-32, intracystic bleomycin, or radiosurgery, and those who were pregnant or with limited English proficiency, were excluded from enrollment. Those with premorbid neurological or neurodevelopmental conditions did not receive protocol-based cognitive evaluations. This study was approved by the Institutional Review Board, and informed consent was obtained prior to participation (RT2CR; NCT01419067).

\section{Procedure}

Some patients were selected for surgical resection based upon assessment and consultation by the neurosurgeon. Participants who received subtotal or no resection were treated with passively-scattered proton therapy. All patients included in this study sample were treated 
with proton beam therapy. Total cumulative dose was 54 CGE using daily fractions of 1.8 CGE and a $5 \mathrm{~mm}$ clinical target volume.

Demographic and clinical variables were extracted from the study database and medical charts. Extent of preoperative hypothalamic involvement (HI) was categorized as having no $\mathrm{HI}$ (grade 0), anterior HI (grade 1), and anterior as well as posterior HI including the mammillary bodies (grade 2) [40-41]. This categorization was based on preoperative neuroimaging after symptom onset. Extent of surgery was categorized as no surgery, placement of a catheter, or resection. Cerebrospinal fluid (CSF) diversion procedures included ventriculoperitoneal (VP) shunting and endoscopic third ventriculostomy (ETV). DI was categorized as present or not based on whether the patient was permanently placed on desmopressin prior to baseline cognitive assessment. The demographic characteristics of the sample are presented in Table 1. As indicated, Cp patients ranged in age from 0.99 to 20.15 years $(M=9.81, S D=4.42)$ at baseline and were roughly balanced by gender $(49 \%$ males). Parent demographic data included gender (16 males, 80 females at baseline; 15 males, 63 female at year 1) and highest level of parental education obtained ( $M=14.79$, SD $=2.25$ at baseline; $\mathrm{M}=14.88, \mathrm{SD}=2.09$ at year 1 ), as a proxy measure of SES.

\section{Measures}

Parents completed the Brief Symptom Inventory (BSI) as a self-report measure of psychological distress within the past week. This measure has well established reliability (e.g., alpha coefficient $=0.70-0.88$ ) and validity (e.g., highly correlated with the SCL-90-R subscales, with correlations from 0.88 to 0.94 ) and has been previously used with the oncology population [42-44]. This questionnaire assesses 9 symptom dimensions across 3 global indices [45]. For the purpose of this study, the researchers looked specifically at the Anxiety and Depression dimensions as well as Global Severity Index (GSI) and Positive Symptom Distress Index (PSDI). The GSI is a measure of overall psychological distress level; the PSDI is a measure of symptom intensity. Scores on the BSI are reported in terms of standardized T-scores, with a mean of 50 and standard deviation of 10, with higher scores indicating higher levels of distress.

Patients completed a neurocognitive assessment at baseline (pre-treatment; $\mathrm{n}=96$ ) as well as 1 year after completion of proton therapy $(n=73)$. An age-tailored comprehensive neuropsychological battery was administered by a trained psychological examiner. Measures selected for these analyses included measures of intellectual functioning (age-appropriate Wechsler scales [46-48]), attention (Conners' Continuous Performance Test-II [CPT-II] [49]), executive function (Wechsler Working Memory Index [WMI] [46-48], Color-Word Interference from the Delis-Kaplan Executive Function System [D-KEFS] [50], Behavior Rating Inventory of Executive Function [BRIEF] Parent Form [51]), memory (ageappropriate version of the California Verbal Learning Test [CVLT] [52-53]), adaptive function (Adaptive Behavior Assessment System, $2^{\text {nd }}$ Edition [ABAS-II] Parent Form [54]), psychosocial function (Behavior Assessment System for Children, $2^{\text {nd }}$ Edition [BASC-2] Parent Rating Scale [55]), and fine motor skills (Grooved Pegboard [56]). 


\section{Statistics}

One sample t-tests were performed to compare mean baseline BSI scores to normative means and chi-square analysis was used to compare the proportion of clinically elevated BSI scores $(t>63)$ to normative expectations $(10 \%)$. Linear mixed effects models were used to evaluate change over the first year as well as to identify predictors of baseline performance and change over time. Univariate predictors included patient gender, age at baseline, degree of HI, presence of DI, extent of surgical resection, presence of CSF diversion, parent gender, parental education as a proxy for SES, and all cognitive subtests listed above. Standard scores between 85 and 115, scaled scores between 7 and 13, t-scores between 40 and 50, and $\mathrm{z}$-scores between -1.00 and 1.00 were considered average.

\section{RESULTS}

At baseline, t-tests indicated parents reported significantly higher levels of distress than normative means on Anxiety, Depression, GSI, and PSDI BSI scales (Table 2). Further, chisquare analyses revealed that clinical levels of anxiety and PSDI at baseline were significantly higher than expected based on population norms (Table 2).

Linear mixed effects models indicated BSI scales (Depression, Anxiety, GSI, PSDI) decreased over time; however, only the decrease in Anxiety was statistically significant (Table 3). At 1 year after completion of proton therapy, both t-tests and chi-square analyses revealed an elevation in PSDI (Table 2). Linear mixed effects models indicated parent report of child executive dysfunction (e.g., BRIEF Global Executive Composite) and behavioral issues (e.g., BASC-2 Internalizing Problems) play a more significant role in predicting parental distress at baseline $(\mathrm{p}<.05)$ than patients' cognitive performance or medical status (Table 4). However, there was evidence of isolated significant findings in the opposite direction as hypothesized (i.e., lower CPT-II Overall Index predicted higher Depression, and better D-KEFS Color Word Inhibition Switching predicted higher Anxiety). One medical variable was in the hypothesized direction (greater number of surgeries predicted higher GSI). Given this finding of potential discrepancy between parent report of cognitive skills and child performance on cognitive measures of the same construct, we created a discrepancy score for working memory (BRIEF WM scale z-score - Wechsler WMI z-score) and calculated correlations between this discrepancy score and BSI indices. These correlations revealed that a greater discrepancy (parent negative reporting style) correlated significantly with Depression, GSI and PSDI BSI indices, with a trend for correlation with the Anxiety BSI index (Table 5). Given that linear mixed effect models showed a significant reduction in Anxiety over time ( $p<.05$ ), further analysis was conducted to explore predictors of change for this BSI scale. It was suggested that only extensive hypothalamic involvement at baseline predicted the reduction in Anxiety ( $p<.05)$ (Table 4).

\section{DISCUSSION}

This study demonstrated that parents of children diagnosed with $\mathrm{Cp}$ are experiencing distress prior to and one-year following tumor-directed treatment. More specifically, parents reported higher levels of distress than normative averages at baseline on Anxiety, Depression, Global Severity and Positive Symptom Distress BSI scales, with the rate of 
clinically elevated scores significantly exceeding the normative expectation of $10 \%$ for Anxiety (19\%) and Positive Symptom Distress (16\%). At one year follow-up, Positive Symptom Distress remained higher than normative means with a higher than expected rate of clinical elevation (15\%). The group had mean values within the average normative range suggesting some, but not all, parents were distressed. All indices of parental distress showed a decrease over time but only parent reported Anxiety reached significance. Interestingly, parental distress was largely unrelated to the child's medical status or cognitive performance on examiner-administered tasks, with the exception of isolated, perhaps spurious, variables. However, parent perceptions of child cognitive difficulties (versus child performance) was predictive of their distress (e.g., BRIEF Global Executive Composite, BASC-2 Internalizing Problems Index). Of particular note, the more discrepant parent report of child cognitive performance was from their child's actual cognitive performance (negative reporting style), the more distressed the parent reported being on the BSI.

Compared to the existing literature, the current findings add mixed support. Consistent with the greater literature base, parental distress persists over time for some parents. That is, while many parents are coping well, particularly a year after treatment initiation, there is a subset that continues to be distressed and may profit from early intervention. As previously discussed, a significant number of parents of pediatric cancer patients experience psychological distress, anxiety, and symptoms of post-traumatic-stress even after termination of their child's cancer treatments, with some parents experiencing psychological symptoms up to 5 years post-treatment [1-15]. Inconsistent with the literature, our findings suggest that parent gender is not predictive of parental distress. For example, some research has found maternal caregivers to report more psychological distress and perceived family conflict than their spouses [16]. This may best be explained by differences in specific measures used across studies or a small percentage of male caregivers in the current study. In addition, parental education as a measure of SES was not predictive of parental distress as has been previously shown in the literature. This may suggest that parental education is not the best proxy measure of SES.

A number of meaningful conclusions with clinical implications can be drawn from this study. First, the findings may suggest children having greater cognitive and behavioral issues in the real-world setting have parents that are most distressed. Alternatively, and perhaps more importantly, these findings may best be explained by a negative parent reporting style; whereby, the most distressed parents overly report negative child characteristics. This is similar to the findings in the adult breast cancer literature whereby women who are more depressed report greater cognitive problems, irrespective of their actual cognitive performance [57].

Research has shown problem-solving skills training can be used to address a wide range of emotional problems including depression and anxiety arising from chronic conditions such as cancer [58-62]. Problem-solving skills training was developed to target parental distress (not psychopathology), and could be adapted to specifically address illness related stressors. For example, Sahler et al., found caregivers of children recently diagnosed with cancer are distressed regardless of specific oncological diagnosis and the Bright IDEAS Problem Solving Skills Training is an acceptable intervention that helped to alleviate this distress 
[60-61]. Problem-solving intervention focuses on developing constructive problem-solving attitudes and skills with the aims of enhancing psychological and behavioral functioning [62]. Within the context of chronic illness, individuals learn new skills and strategies, thereby improving one's quality of life. This technique may be most appropriate to parents of children with certain medical conditions. For example, given that a higher number of surgeries predicted increased GSI, it may be beneficial to teach coping skills to these parents to specifically get through surgeries with the least distress. Further, increased $\mathrm{HI}$ at baseline predicted a decrease in anxiety overtime. Teaching coping strategies to parents for caring for a child with multiple endocrinopathies and their complicated medical management may be beneficial.

Second, monitoring and intervening with parents appears warranted. This includes immediate and ongoing screeners and support for families during diagnosis and treatment of $\mathrm{Cp}$, with attention to parents who report significantly more distress or negativity as treatment continues. While some distress may resolve without intervention, early intervention could expedite the natural adjustment process and/or provide future protection (e.g., in the case of relapse). Furthermore, social support, familial cohesion, and adaptability have all been found to be associated with lower parental anxiety, distress and symptoms consistent with posttraumatic-stress symptoms [17, 19-25]. Therefore, access to social support via support groups, as well as cognitive behavioral individual and family therapy for parents may prove promising. Future research could compare problem-solving training for caregivers to support groups, cognitive behavioral therapy, and/or family therapy.

This study assessed parental distress within a large group of patients with Cp receiving proton beam radiation therapy, which has not previously occurred in the literature. Ultimately, this allows for better understanding of parental socio-emotional functioning as their children undergo modern medical intervention. In addition, better understanding of parental distress within this population can inform psychological intervention. However, there are limitations associated with this study. First, we do not have information on psychological interventions provided to parents; while we anticipate the rate of parental intervention was low based on patterns of service provision at this site, this may have impacted levels of distress over time. Second, lack of knowledge regarding caregiver premorbid psychiatric history and/or temperament limits our understanding of the causal or correlational relationship with long-term psychosocial functioning as some research has found a positive relationship between parent self-efficacy, adaptive style, and short-and longterm psychosocial functioning, regardless of treatment outcomes [26-30, 63]. Future studies may consider and control for premorbid parental conditions as well as investigate changes in parental distress across time and determine when socio-emotional functioning returns to normative baseline rates, with or without intervention. Finally, given prior findings of increased distress associated with parenting in general, parents of healthy children, matched on socioeconomic factors, could be included as a control group in future work [64].

\section{Acknowledgments}

The authors thank the patients and their families who volunteered their time to participate in this study. We would also like to thank Sean Phipps, Ph.D. for his editorial input. This work was supported, in part, by the National Cancer Institute (St. Jude Cancer Center Support [CORE] Grant [P30-CA21765]) and the American Lebanese 
Syrian Associated Charities (ALSAC). Portions of this paper were presented at the annual meeting of the International Neuropsychological Society in Boston, MA, 2016.

\section{LIST OF ABBREVIATIONS}

\begin{tabular}{|c|c|}
\hline ABAS-II & Adaptive Behavior Assessment System - Second Edition \\
\hline BASC-2 & Behavior Assessment System for Children - Second Edition \\
\hline BRIEF & Behavior Rating Inventory of Executive Function \\
\hline BSI & Brief Symptom Inventory \\
\hline CGE & Cobalt Gray Equivalent \\
\hline Cp & Craniopharyngioma \\
\hline CPT-II & Continuous Performance Test - Second Edition \\
\hline CSF & Cerebrospinal Fluid \\
\hline CVLT & California Verbal Learning Test \\
\hline DI & Diabetes Insipidus \\
\hline DKEFS & Delis-Kaplan Executive Function System \\
\hline ETV & Endoscopic Third Ventriculostomy \\
\hline GHQ-30 & General Health Questionnaire - 30 \\
\hline GSI & Global Severity Index \\
\hline HI & Hypothalamic Involvement \\
\hline $\mathbf{M}$ & Mean \\
\hline mm & millimeters \\
\hline PSDI & Positive Symptom Distress Index \\
\hline QoL & Quality of Life \\
\hline SD & Standard Deviation \\
\hline SES & Socioeconomic Status \\
\hline SSERQ & Situation-Specific Emotional Reaction Questionnaire \\
\hline VP & Venriculoperitoneal \\
\hline WMI & Working Memory Index \\
\hline
\end{tabular}

\section{References}

1. Sloper P. Predictors of distress in parents of children with cancer: A prospective study. Journal of pediatric psychology. 2000; 25(2):79-91. [PubMed: 10820946]

Pediatr Blood Cancer. Author manuscript; available in PMC 2019 October 01. 
2. Wijnberg-Williams BJ, Kamps WA, Klip EC, Hoekstra-Weebers JE. Psychological distress and the impact of social support on fathers and mothers of pediatric cancer patients: Long-term prospective results. Journal of Pediatric Psychology. 2006; 31(8):785-792. [PubMed: 16251479]

3. Kazak AE, Alderfer M, Rourke MT, Simms S, Streisand R, Grossman JR. Posttraumatic stress disorder (PTSD) and posttraumatic stress symptoms (PTSS) in families of adolescent childhood cancer survivors. Journal of Pediatric Psychology. 2004; 29(3):211-219. [PubMed: 15131138]

4. Brown RT, Madan-Swain A, Lambert R. Posttraumatic stress symptoms in adolescent survivors of childhood cancer and their mothers. Journal of Traumatic Stress. 2003; 16(4):309-318. [PubMed: 12895012]

5. Boman K, Lindahl A, Björk O. Disease-related distress in parents of children with cancer at various stages after the time of diagnosis. Acta Oncologica. 2003; 42(2):137-146. [PubMed: 12801132]

6. Maurice-Stam H, Oort FJ, Last BF, Grootenhuis MA. Emotional functioning of parents of children with cancer: the first five years of continuous remission after the end of treatment. PsychoOncology. 2008; 17(5):448-459. [PubMed: 17828715]

7. Lindahl Norberg A, Boman KK. Parent distress in childhood cancer: A comparative evaluation of posttraumatic stress symptoms, depression and anxiety. Acta Oncologica. 2008; 47(2):267-274. [PubMed: 17851875]

8. Rabineau KM, Mabe PA, Vega RA. Parenting stress in pediatric oncology populations. Journal of Pediatric Hematology/Oncology. 2008; 30(5):358-365. [PubMed: 18458569]

9. McGrath P. Beginning treatment for childhood acute lymphoblastic leukemia: insights from the parents' perspective. Oncology Nursing Forum. 2002; 29(6):988-996. [PubMed: 12096296]

10. Zeltzer LK, Recklitis C, Buchbinder D, Zebrack B, Casillas J, Tsao JC, ... Krull K. Psychological status in childhood cancer survivors: a report from the Childhood Cancer Survivor Study. Journal of Clinical Oncology. 2009; 27(14):2396-2404. [PubMed: 19255309]

11. Kazak AE, Prusak A, McSherry M, Simms S, Beele D, Rourke M, ... Lange B. The Psychosocial Assessment Tool (PAT)@: Pilot data on a brief screening instrument for identifying high risk families in pediatric oncology. Families, Systems, \& Health. 2001; 19(3):303.

12. Zeltzer LK, Lu Q, Leisenring W, Tsao JC, Recklitis C, Armstrong G, ... Ness KK. Psychosocial outcomes and health-related quality of life in adult childhood cancer survivors: a report from the childhood cancer survivor study. Cancer Epidemiology and Prevention Biomarkers. 2008; 17(2): 435-446.

13. Stam H, Grootenhuis M, Last B. Social and emotional adjustment in young survivors of childhood cancer. Supportive Care in Cancer. 2001; 9(7):489-513. [PubMed: 11680830]

14. Stam H, Grootenhuis M, Brons P, Caron H, Last B. Health-related quality of life in children and emotional reactions of parents following completion of cancer treatment. Pediatric Blood and Cancer. 2005; 47(3):312-319.

15. Grootenhuis MA, Last BF. Predictors of parental emotional adjustment to childhood cancer. Psycho-Oncology. 1997; 6:115-128. [PubMed: 9205969]

16. Yeh CH. Gender differences of parental distress in children with cancer. Journal of Advanced Nursing. 2002; 38(6):598-606. [PubMed: 12067399]

17. Sloper P. Predictors of distress in parents of children with cancer: A prospective study. Journal of Pediatric Psychology. 2000; 25(2):79-91. [PubMed: 10820946]

18. Manne S, Miller D, Meyers P, Wollner N, Steinherz P, Redd WH. Depressive symptoms among parents of newly diagnosed children with cancer: A 6-month follow-up study. Children's Health Care. 1996; 25(3):191-209.

19. Hoekstra-Weebers JE, Jaspers JP, Kamps WA, Klip EC. Risk factors for psychological maladjustment of parents of children with cancer. Journal of the American Academy of Child \& Adolescent Psychiatry. 1999; 38(12):1526-1535. [PubMed: 10596253]

20. Anderson VA, Catroppa C, Haritou F, Morse S, Pentland L, Rosenfeld J, Stargatt R. Predictors of acute child and family outcome following traumatic brain injury in children. Pediatric neurosurgery. 2001; 34(3):138-148. [PubMed: 11359102]

21. Verhaeghe S, Defloor T, Grypdonck M. Stress and coping among families of patients with traumatic brain injury: a review of the literature. Journal of clinical nursing. 2005; 14(8):10041012. [PubMed: 16102152] 
22. Anderson MI, Simpson GK, Morey PJ. The impact of neurobehavioral impairment on family functioning and the psychological well-being of male versus female caregivers of relatives with severe traumatic brain injury: multigroup analysis. The Journal of head trauma rehabilitation. 2013; 28(6):453-463. [PubMed: 22832371]

23. Hoekstra-Weebers JE, Jaspers JP, Kamps WA, Klip EC. Psychological adaptation and social support of parents of pediatric cancer patients: A prospective longitudinal study. Journal of Pediatric Psychology. 2001; 26(4):225-235. [PubMed: 11329482]

24. Dockerty JD, Williams SM, McGee R, Skegg DC. Impact of childhood cancer on the mental health of parents. Pediatric Blood \& Cancer. 2000; 35(5):475-483.

25. Kazak AE, Stuber ML, Barakat LP, Meeske K, Guthrie D, Meadows AT. Predicting posttraumatic stress symptoms in mothers and fathers of survivors of childhood cancers. Journal of the American Academy of Child \& Adolescent Psychiatry. 1998; 37(8):823-831. [PubMed: 9695444]

26. Norberg AL, Lindblad F, Boman KK. Support-seeking, perceived support, and anxiety in mothers and fathers after children's cancer treatment. Psycho-Oncology. 2006; 15(4):335-343. [PubMed: 16106491]

27. Phipps S. Adaptive style in children with cancer: Implications for a positive psychology approach. Journal of Pediatric Psychology. 2007; 32(9):1055-1066. [PubMed: 17698880]

28. Phipps S, Larson S, Long A, Rai SN. Adaptive style and symptoms of posttraumatic stress in children with cancer and their parents. Journal of Pediatric Psychology. 2005; 31(3):298-309. [PubMed: 15917493]

29. Erickson SJ, Gerstle M, Montague EQ. Repressive adaptive style and self-reported psychological functioning in adolescent cancer survivors. Child Psychiatry \& Human Development. 2008; 39(3): 247-260. [PubMed: 17952587]

30. Weinberger DA, Schwartz GE, Davidson RJ. Low-anxious, high-anxious, and repressive coping styles: psychometric patterns and behavioral and physiological responses to stress. Journal of Abnormal Psychology. 1979; 88(4):369. [PubMed: 479459]

31. Weinberger DA. The construct validity of the repressive coping style. In: Singer J, editorRepression and Dissociation: Implications for personality theory, psychopathology, and health. Chicago, IL: The University of Chicago Press; 1990. 337-386.

32. Pereira AM, Schmid EM, Schutte PJ, Voormolen JH, Biermasz NR, Van Thiel SW, ... Romijn JA. High prevalence of long-term cardiovascular, neurological and psychosocial morbidity after treatment for craniopharyngioma. Clinical Endocrinology. 2005; 62(2):197-204. [PubMed: 15670196]

33. Poretti A, Grotzer MA, Ribi K, Schonle E, Boltshauser E. Outcome of craniopharyngioma in children: long-term complications and quality of life. Developmental Medicine and Child Neurology. 2004; 46(4):220. [PubMed: 15077699]

34. Pedreira CC, Stargatt R, Maroulis H, Rosenfeld J, Maixner W, Warne GL, Zacharin MR. Health related quality of life and psychological outcome in patients treated for craniopharyngioma in childhood. Journal of Pediatric Endocrinology and Metabolism. 2006; 19(1):15-24. [PubMed: 16509524]

35. Kendall-Taylor P, Jönsson PJ, Abs R, Erfurth EM, Koltowska-Häggström M, Price DA, Verhelst J. The clinical, metabolic and endocrine features and the quality of life in adults with childhoodonset craniopharyngioma compared with adult-onset craniopharyngioma. European Journal of Endocrinology. 2005; 152(4):557-567. [PubMed: 15817911]

36. Sands SA, Milner JS, Goldberg J, Mukhi V, Moliterno JA, Maxfield C, Wisoff JH. Quality of life and behavioral follow-up study of pediatric survivors of craniopharyngioma. Journal of Neurosurgery: Pediatrics. 2005; 103(4):302-311. [PubMed: 16270681]

37. Pulsifer MB, Sethi RV, Kuhlthau KA, MacDonald SM, Tarbell NJ, Yock TI. Early cognitive outcomes following proton radiation in pediatric patients with brain and central nervous system tumors. International Journal of Radiation Oncology*Biology*Physics. 2015; 93(2):400-407.

38. Kahalley LS, Ris MD, Grosshans DR, Okcu MF, Paulino AC, Chintagumpala M, ... Mahajan A. Comparing intelligence quotient change after treatment with proton versus photon radiation therapy for pediatric brain tumors. Journal of Clinical Oncology. 2016; 34(10):1043-1049. [PubMed: 26811522] 
39. Fournier-Goodnight AS, Ashford JM, Merchant TE, Boop FA, Indelicato DJ, Wang L, Zhang H, Conklin HM. Neurocognitive functioning in pediatric craniopharyngioma: performance before treatment with proton therapy. Journal of Neuro-Oncology. 2017 in press.

40. Puget S, Garnett M, Wray A, Grill J, Habrand JL, Bodaert N, ... Sainte-Rose C. Pediatric craniopharyngiomas: classification and treatment according to the degree of hypothalamic involvement. Journal of Neurosurgery: Pediatrics. 2007; 106(1):3-12. [PubMed: 17233305]

41. Özyurt J, Thiel CM, Lorenzen A, Gebhardt U, Calaminus G, Warmuth-Metz M, Müller HL. Neuropsychological outcome in patients with childhood craniopharyngioma and hypothalamic involvement. The Journal of Pediatrics. 2014; 164(4):876-881. [PubMed: 24507865]

42. Sahin NH, Durak AB, Uğurtaş S. The validity, reliability and factor structure of the Brief Symptom Inventory (BSI). Turk psikiyatri dergisi= Turkish journal of psychiatry. 2002; 13(2):125-135. [PubMed: 12794665]

43. Recklitis CJ, Rodriguez P. Screening childhood cancer survivors with the brief symptom inventory-18: classification agreement with the symptom checklist-90-revised. Psycho-Oncology. 2007; 16(5):429-436. [PubMed: 16929465]

44. Stefanek ME, Derogatis LP, Shaw A. Psychological distress among oncology outpatients: prevalence and severity as measured with the Brief Symptom Inventory. Psychosomatics. 1987; 28(10):530-539. [PubMed: 3432516]

45. Derogatis LR, Melisaratos N. The brief symptom inventory: an introductory report. Psychological medicine. 1983; 13(3):595-605. [PubMed: 6622612]

46. Wechsler D. Wechsler adult intelligence scale. 4. New York: Psychological Corporation; 2008.

47. Wechsler D. Wechsler intelligence scale for children. 4. San Antonio, TX: The Psychological Corporation; 2003.

48. Wechsler D. Wechsler preschool and primary scale of intelligence. 3. San Antonio, TX: Psychological Corporation; 2002.

49. Conners KC. MHS Staff. Conners' Continuous Performance Test, version 5. 2. Toronto, ON: Multi-Health Systems; 2004.

50. Delis DC, Kaplan E, Kramer JH. Delis-Kaplan executive system. San Antonio, TX: The Psychological Corporation; 2001.

51. Gioia GA, Isquith PK, Guy SC, Kenworthy L. Behavior rating inventory of executive function. Lutz, FL: Psychological Assessment Resources; 2000.

52. Delis DC, Kramer JH, Kaplan E, Ober BA. California verbal learning test, children's version. San Antonio, TX: The Psychological Corporation; 1994.

53. Delis DC, Kramer JH, Kaplan E, Ober BA. California verbal learning test, 2nd edition, adult version. San Antonio, TX: The Psychological Corporation; 2000.

54. Harrison PL, Oakland T. Adaptive behavior assessment system. 2. San Antonio, TX: Harcourt Assessment; 2003.

55. Reynolds CR, Kamphaus RW. Behavior assessment system for children. 2. Circle Pines, MN: AGS Publishing; 2004.

56. Lafayette Instrument. Grooved pegboard task. Lafayette, IN: Lafayette Instrument Company; 2003.

57. Paquet L, Verma S, Collins B, Chinneck A, Bedard M, Song X. Testing novel account of the dissociation between self-reported memory problems and memory performance in chemotherapytreated breast cancer survivors. Psycho-Oncology. 2017

58. Nezu AM, Nezu CM, Felgoise SH, McClure KS, Houts PS. Project Genesis: assessing the efficacy of problem-solving therapy for distressed adult cancer patients. Journal of Consulting and Clinical Psychology. 2003; 71(6):1036. [PubMed: 14622079]

59. Nezu AM, Nezu CM, Friedman SH, Faddis S, Houts PS. Helping Cancer Patients Cope: A problem-solving approach. American Psychological Association; 1998.

60. Sahler OJZ, Dolgin MJ, Phipps S, Fairclough DL, Askins MA, Katz ER, ... Butler RW. Specificity of problem-solving skills training in mothers of children newly diagnosed with cancer: results of a multisite randomized clinical trial. Journal of Clinical Oncology. 2013; 31(10):1329-1335.

[PubMed: 23358975] 
61. Sahler OJZ, Fairclough DL, Phipps S, Mulhern RK, Dolgin MJ, Noll RB, ... Butler RW. Using problem-solving skills training to reduce negative affectivity in mothers of children with newly diagnosed cancer: report of a multisite randomized trial. Journal of Consulting and Clinical Psychology. 2005; 73(2):272. [PubMed: 15796635]

62. Dobson KS, editorHandbook of cognitive-behavioral therapies. Guilford Press; 2009.

63. Harper FW, Peterson AM, Uphold H, Albrecht TL, Taub JW, Orom H, ... Penner LA. Longitudinal study of parent caregiving self-efficacy and parent stress reactions with pediatric cancer treatment procedures. Psycho-Oncology. 2013; 22(7):1658-1664. [PubMed: 23034930]

64. Noll RB, Hawkins A, Vannatta K, Gartstein MA, Davies W, Bukowski WM. Comparing parental distress for families with children who have cancer and matched comparison families without children with cancer. Family Systems Medicine. 1995; 13(1):11.

65. Kearney JA, Salley CG, Muriel AC. Standards of psychosocial care for parents of children with cancer. Pediatric Blood \& Cancer. 2015; 62(S5):S574-S580. 


\section{TABLE 1}

\section{Demographic and clinical characteristics}

\begin{tabular}{|c|c|c|}
\hline Variable & $\mathbf{n}$ & Percentage \\
\hline \multicolumn{3}{|l|}{ Patient Gender } \\
\hline Male & 47 & 49.0 \\
\hline Female & 49 & 51.0 \\
\hline \multicolumn{3}{|l|}{ Parent/Respondent Gender } \\
\hline Male & 16 & 16.7 \\
\hline Female & 80 & 83.3 \\
\hline \multicolumn{3}{|l|}{ Hypothalamic Involvement ${ }^{a}$} \\
\hline Grade 0 & 17 & 17.7 \\
\hline Grade 1 & 26 & 27.1 \\
\hline Grade 2 & 53 & 55.2 \\
\hline \multicolumn{3}{|l|}{ Diabetes Insipidus $b$} \\
\hline Yes & 52 & 54.2 \\
\hline No & 44 & 45.8 \\
\hline \multicolumn{3}{|l|}{ Surgical Category $^{c}$} \\
\hline Resection & 70 & 72.9 \\
\hline Catheter & 16 & 16.7 \\
\hline No Surgery & 10 & 10.4 \\
\hline \multicolumn{3}{|l|}{ CSF Diversion $^{d}$} \\
\hline Yes & 33 & 34.4 \\
\hline No & 63 & 65.6 \\
\hline \multicolumn{3}{|l|}{ Growth Hormone Peak Value $e^{e}$} \\
\hline Normal & 15 & 19.2 \\
\hline Deficient & 56 & 71.8 \\
\hline \multirow[t]{2}{*}{ Severe } & 7 & 9.0 \\
\hline & Mean \pm SD & Range \\
\hline Age at Baseline Assessment & $9.81 \pm 4.42$ & $0.99-20.15$ \\
\hline Number of Surgeries & $1.58 \pm 1.23$ & $0.00-8.00$ \\
\hline Growth Hormone Peak Value $e^{e}$ & $2.42 \pm 4.49$ & $0.10-29.20$ \\
\hline
\end{tabular}

a Grade 0 - No hypothalamic involvement; Grade 1 - Anterior hypothalamic involvement; Grade 2 - Anterior and posterior hypothalamic involvement including mammillary bodies and area behind mammillary bodies [40-41]

$b_{\text {Status before proton beam radiation therapy }}$

$c_{\text {Patients with multiple surgeries classified based on most extensive/invasive procedure }}$

$d_{\text {Includes patients who received either CSF shunt or endoscopic third ventriculostomy }}$

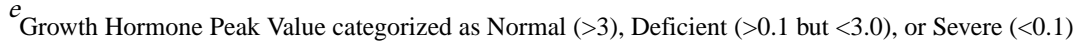

Pediatr Blood Cancer. Author manuscript; available in PMC 2019 October 01. 
TABLE 2

Baseline and year 1 parental distress (BSI indices) and comparison with normative expectations

\begin{tabular}{|c|c|c|c|c|}
\hline BSI Measure & Mean \pm SD & p-value ${ }^{a}$ & \% Elevated & p-value $b$ \\
\hline Baseline Depression & $52.38 \pm 8.90$ & $0.0104^{*}$ & 12 & 0.414 \\
\hline Baseline Anxiety & $52.66 \pm 10.75$ & $0.0174^{*}$ & 19 & $0.001^{*}$ \\
\hline Baseline Global Severity Index & $53.05 \pm 9.88$ & $0.0032^{*}$ & 13 & 0.247 \\
\hline Baseline Positive Symptom Distress Index & $54.54 \pm 8.21$ & $<.0001^{*}$ & 16 & $0.021^{*}$ \\
\hline Year 1 Depression & $50.93 \pm 8.67$ & 0.3617 & 9 & 0.480 \\
\hline Year 1 Anxiety & $50.05 \pm 10.21$ & 0.9635 & 7 & 0.937 \\
\hline Year 1 Global Severity Index & $51.16 \pm 10.66$ & 0.3539 & 9 & 0.480 \\
\hline Year 1 Positive Symptom Distress Index & $53.23 \pm 9.80$ & $0.0079^{*}$ & 15 & $0.001^{*}$ \\
\hline \multicolumn{5}{|c|}{${ }^{a}$-values obtained using t-tests comparing sample means with a normative mean of 50 and SD of 10} \\
\hline \multicolumn{5}{|c|}{$\begin{array}{l}b \\
p \text {-values obtained using chi-square tests, where, in a normative population, } 10 \% \text { would be expected to be "elevated", defined as having a t score } \\
>63\end{array}$} \\
\hline
\end{tabular}




\section{롤}

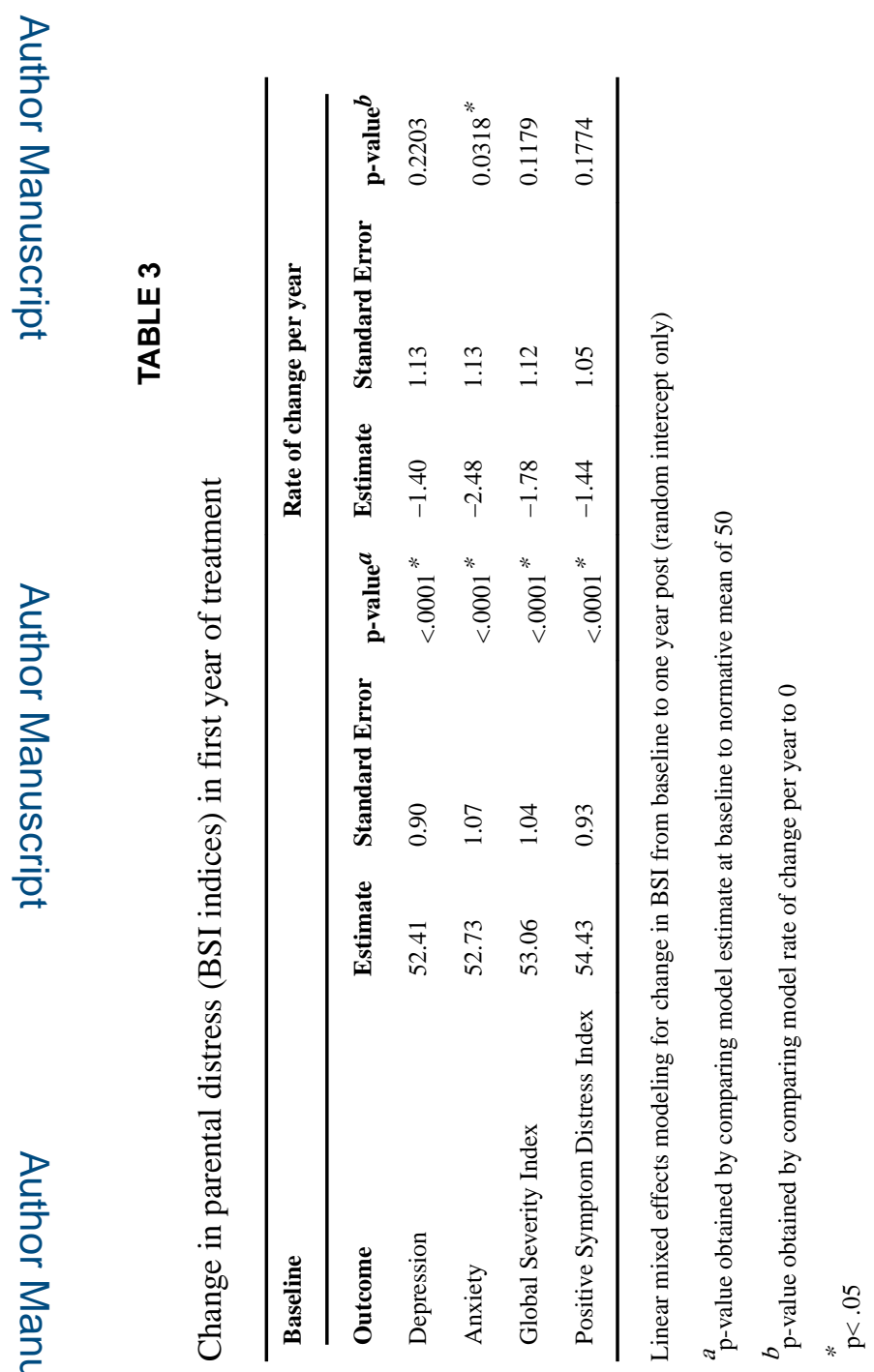

Pediatr Blood Cancer. Author manuscript; available in PMC 2019 October 01. 


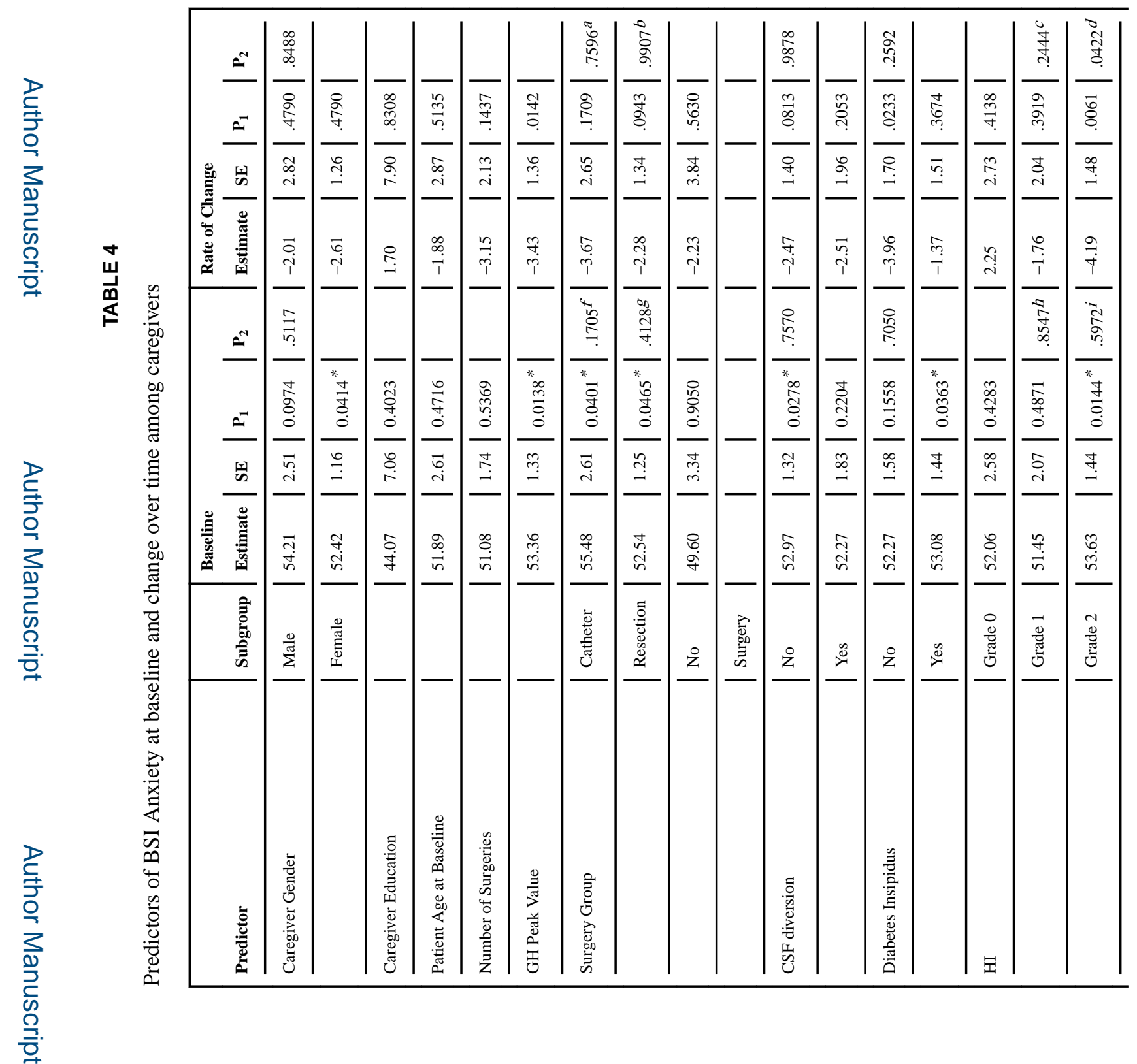

Pediatr Blood Cancer. Author manuscript; available in PMC 2019 October 01. 


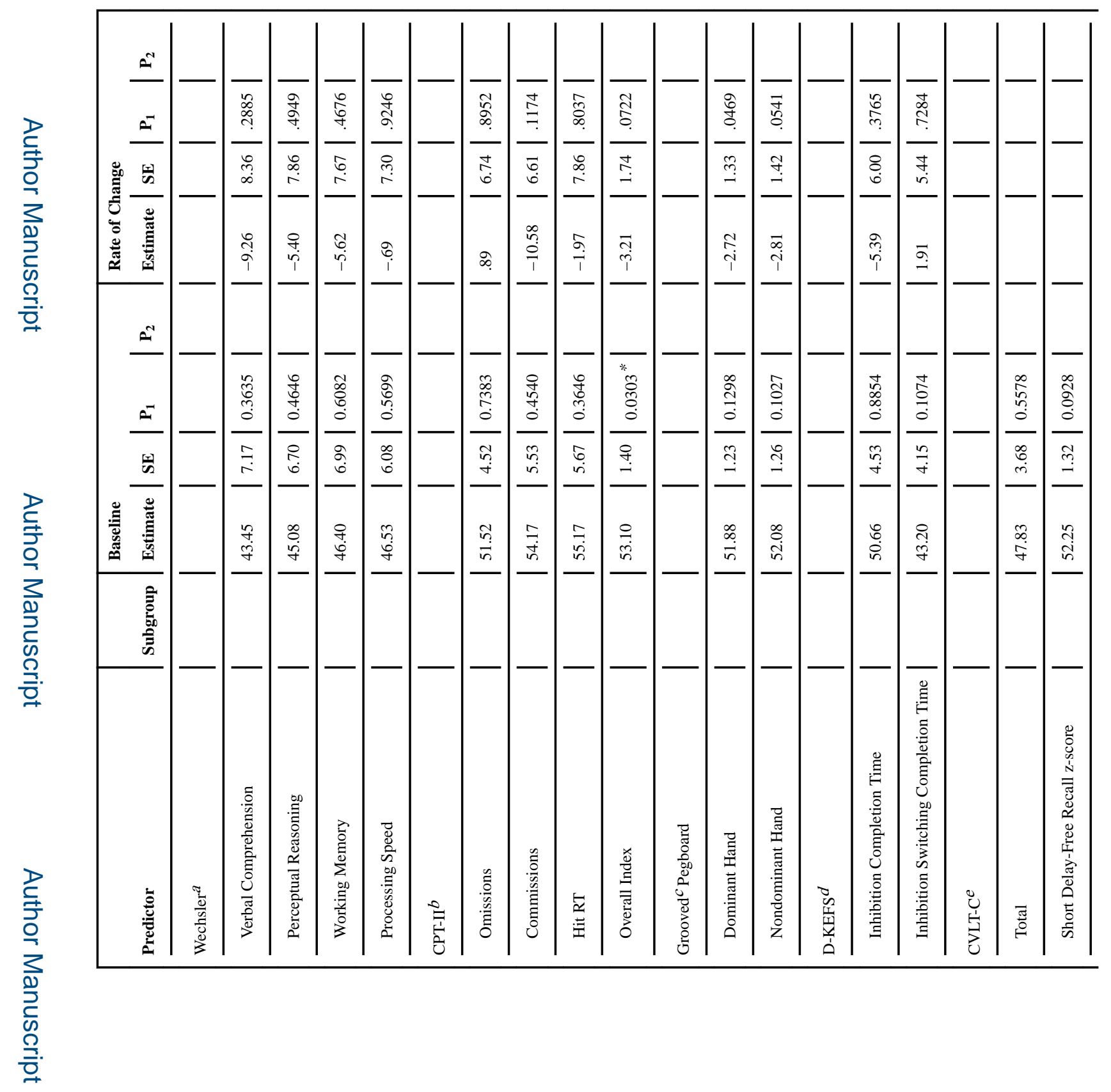

로을 


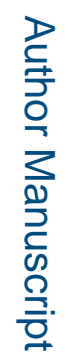
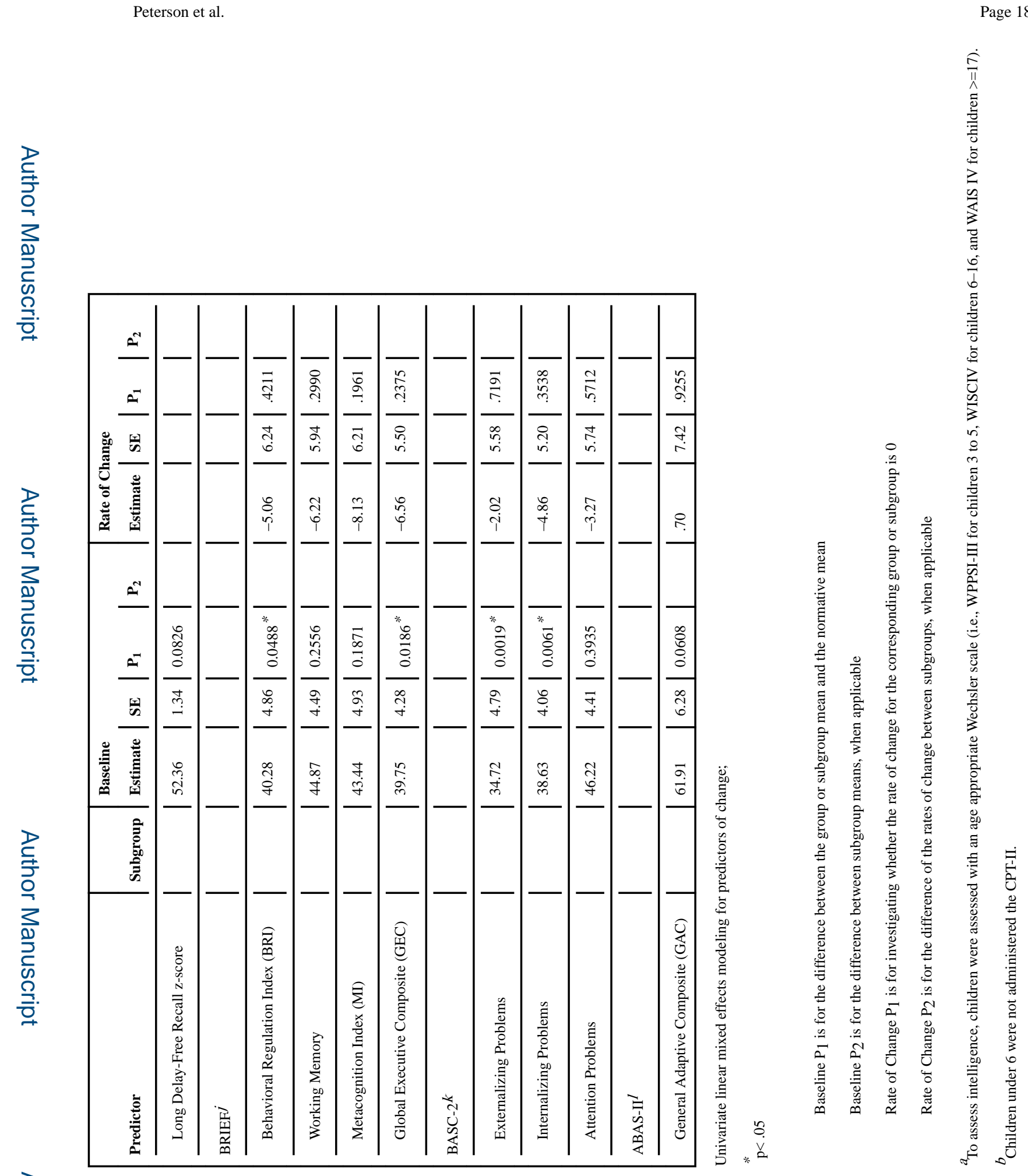

로을

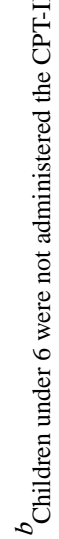

Pediatr Blood Cancer. Author manuscript; available in PMC 2019 October 01. 

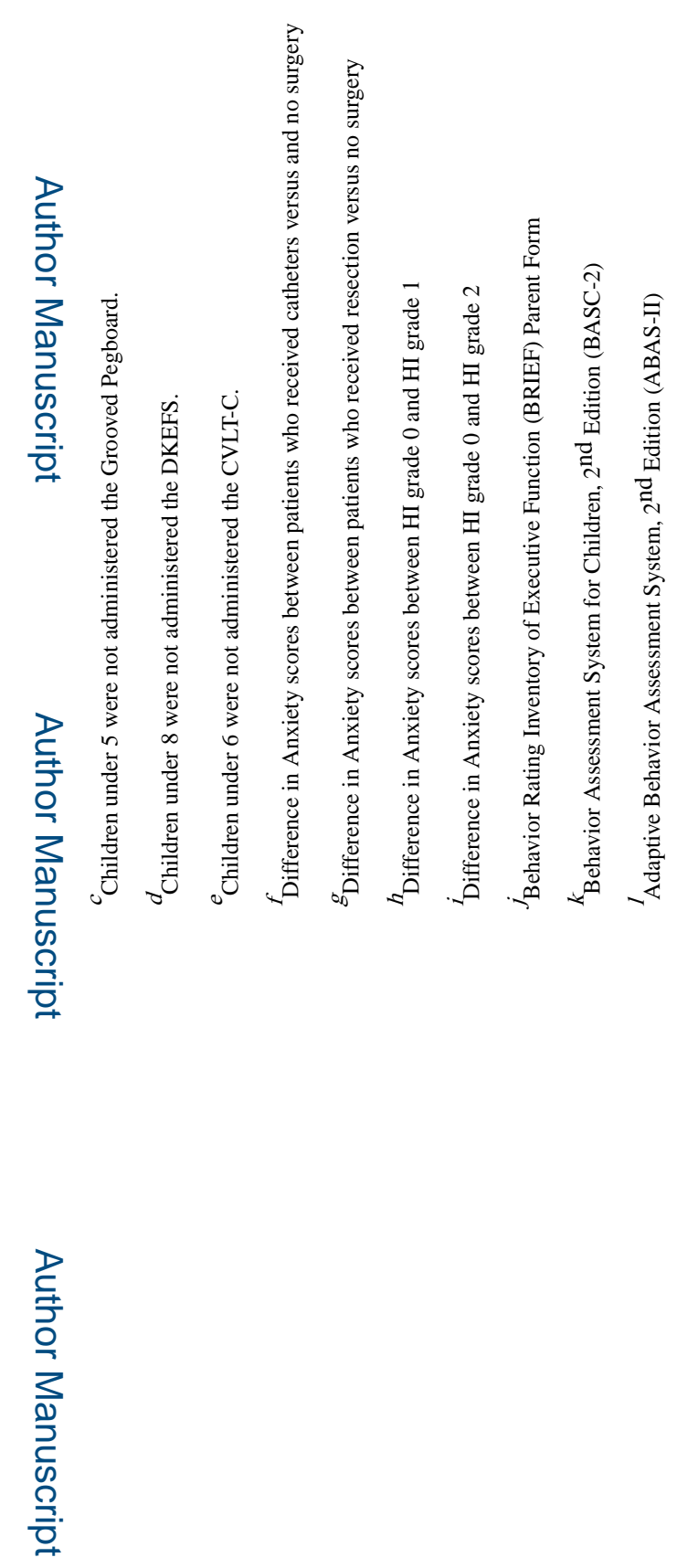

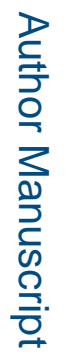

Pediatr Blood Cancer. Author manuscript; available in PMC 2019 October 01. 


\section{TABLE 5}

Parent reporting style and parental distress

\begin{tabular}{lcc}
\hline & Negative Reporting Style $^{a}$ & $\boldsymbol{p}^{\boldsymbol{b}}$ \\
\hline Depression & -0.293 & $0.011^{*}$ \\
Anxiety & -0.228 & $0.050^{\dagger}$ \\
Global Severity Index & -0.381 & $0.001^{*}$ \\
Positive Symptom Distress Index & -0.272 & $0.022^{*}$ \\
\hline
\end{tabular}

${ }^{a}$ Calculated from difference in performance measure of working memory (WISC-IV WMI) and parental report of working memory (BRIEF WM), with larger negative scores indicating a parent reporting higher problems than reflected in performance scores

$b$

${ }_{p}$-values from Pearson correlations

$p^{*}<.05$;

${ }^{t} p .10$ 